\title{
Proporcionalidade e direitos humanos: TEDH e margem de apreciação
}

\author{
Paula Veiga ${ }^{1}$
}

SUMÁRIO: 1. O padrão internacional do princípio da proporcionalidade - algumas notas; 2. O princípio da proporcionalidade e a margem de apreciação no âmbito da CEDH

\section{O padrão internacional do princípio da proporcionali- dade - algumas notas}

A invocação do princípio da proporcionalidade pelo Tribunal Europeu de Direitos Humanos (adiante, TEDH) (e, em geral, embora com menor ênfase, pelos sistemas regionais de protecção de direitos humanos), muito tem contribuído para a difusão deste critério hermenêutico a nível global, ajudando-o a transpor as fronteiras do direito público interno ${ }^{2 / 3}$. O presente discurso insere-se, pois,

1 Faculdade de Direito, Universidade de Coimbra.

2 No direito internacional, a utilização do princípio da proporcionalidade é sobretudo judicial, socorrendo-se desta ferramenta não só o Tribunal Europeu de Direitos Humanos, a Corte Interamericana de Direitos Humanos e a Comissão Africana de Direitos Humanos, mas, também o Tribunal Internacional de Justiça e o Tribunal de Justiça da União Europeia.

3 O que nem sempre será isento de dificuldades. Neste sentido, afirma VitalinO CANAS que "[...] a pretensão universalizante, que está subjacente a algumas das efusivas sínteses inicialmente citadas, esbarra com questões pragmáticas: a propensão "camaleónica» do princípio e das suas derivações, isto é a sua capacidade de se metamorfosear e de se adaptar - mantendo eventualmente a estrutura 
no quadro da mútua influência entre o Direito Constitucional e o Direito Internacional Público, e, em especial, no âmbito do relacionamento entre jurisprudências, aplicado não (como é classicamente conhecido) à gramática dos direitos fundamentais, mas à dos direitos humanos.

A principal questão sobre a qual se pretende reflectir nas linhas que se seguem é, dentro deste contexto, a da relação entre a proporcionalidade e a margem de apreciação na jurisprudência do TEDH, tentando averiguar se essas duas esferas constituirão uma equação do direito público europeu.

Como é sobejamente sabido, no Direito Constitucional - portanto, no direito interno - um dos domínios específicos em que amiúde se lança mão do princípio da proporcionalidade é o da colisão entre direitos fundamentais ${ }^{4}$. Por isso, invocar o princípio da proporcionalidade no âmbito dos direitos humanos não constitui sequer uma grande novidade em termos materiais. Mas, como se defende que as categorias dogmáticas dos direitos fundamentais e dos direitos humanos não são exactamente coincidentes ${ }^{5}$, também não deixa de ser verdade que invocar o princípio da proporcionalidade na gramática dos direitos humanos pode conter diferenças e/ ou novidades.

O padrão internacional do princípio da proporcionalidade decorre, à semelhança do que sucede no direito público interno, do princípio do Estado de direito ${ }^{6}$ e tem vindo a ser enfatizado no Direito dos Direitos Humanos, embora a consagração desse princípio não seja expressa nos principais instrumentos de protecção deste tipo

básica - aos vários ordenamentos, contextos e culturas, leva a que quando focamos aspetos específicos da teoria e da dogmática do princípio da proporcionalidade em distintos ambientes jurídicos nem sempre estejamos a falar da mesma coisa". Do autor, O princípio da proibição do excesso: em especial, na conformação e no controlo de atos legislativos, Tese de Doutoramento, polic., Universidade de Lisboa, pp. 23 e 24.

4 Cfr., artigo $18 .^{\circ},{ }^{\circ}{ }^{\circ} 2$ da CRP.

5 Neste sentido, vide J. J. Gomes Canotilho, Direito Constitucional e Teoria da

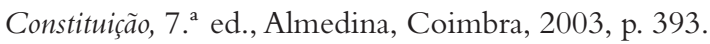

6 Há mesmo quem defenda que o princípio da proporcionalidade é uma verdadeira exigência axiológica do princípio do Estado de direito. 
de direitos. Com efeito, nem a Declaração Universal dos Direitos Humanos (adiante, DUDH), nem os Pactos (o Pacto Internacional dos Direitos Civis e Políticos (adiante, PIDCP) e o Pacto Internacional dos Direitos Económicos, Sociais e Culturais (adiante, PIDESC)) o consagram expressis verbis. A cláusula limitativa de direitos inscrita no n. ${ }^{\circ} 2$ do artigo $29 .^{\circ}$ da DUDH refere, no entanto, que o fim das limitações deve ser o de "satisfazer as justas exigências da moral, da ordem pública e do bem-estar numa sociedade democrática" e o objectivo da limitação de direitos no âmbito do artigo $4 .^{\circ}$ do PIDESC é exclusivamente o de "promover o bem-estar geral numa sociedade democrática". Já no domínio do PIDCP, a proporcionalidade não tem assumido grande relevância, questão que foi enfatizada (e criticada) pelo (então) Comité de Direitos Humanos. De qualquer modo, ao apelar para "justas exigências" há, nestes textos, uma radicação última na ideia de justiça e de balanceamento que é fundamento do princípio da proporcionalidade. A relativa juventude da Carta de Direitos Fundamentais da União Europeia poderá ser uma das razões que justifica, ao contrário do que sucede com outros instrumentos normativos, a consagração expressa do princípio da proporcionalidade no artigo $52 .{ }^{\circ}$.

\section{O princípio da proporcionalidade e a margem de apre- ciação no âmbito da $\mathrm{CEDH}$}

No domínio da Convenção Europeia de Direitos Humanos (adiante, $\mathrm{CEDH}$ ), o princípio da proporcionalidade vem sendo reconhecido como um princípio geral de direito, sobretudo mediante a densificaçãol jurisprudencial que o Tribunal Europeu de Direitos Humanos (adiante, TEDH) vem dando à cláusula convencional "numa

7 Dispõe assim o n. ${ }^{\circ} 1$ do artigo 52. ${ }^{\circ}$ dessa Carta: “Qualquer restrição ao exercício dos direitos e liberdades reconhecidos pela presente Carta deve ser prevista por lei e respeitar o conteúdo essencial desses direitos e liberdades. $\mathrm{Na}$ observância do princípio da proporcionalidade, essas restrições só podem ser introduzidas se forem necessárias e corresponderem efectivamente a objectivos de interesse geral reconhecidos pela União, ou à necessidade de protecção dos direitos e liberdades de terceiros". 
sociedade democrática". Com efeito, não sendo os direitos garantidos e protegidos pela Convenção Europeia de Direitos Humanos absolutos, as limitações emergem por via explícita (como, por exemplo, as necessárias para a "segurança nacional”, a "segurança pública", a "defesa da ordem", etc. - cfr., n. ${ }^{\circ}$ s 2 dos artigos $8 .^{\circ}$ e 9. ${ }^{\circ} \mathrm{CEDH}$ ) ou por via implícita, que são definidas através da jurisprudência do Tribunal. É no que toca a este último tipo de limitações que o Tribunal tem sido, muitas vezes, chamado a analisar a proporcionalidade de uma ingerência.

Se, por definição, qualquer tratado de direitos humanos prioriza direitos, a abordagem de equilíbrio tem marcado o passo da jurisprudência do TEDH. De resto, a lógica de equilíbrio encontra-se na jurisprudência deste Tribunal quando ele equaciona entre o direito e a política, entre o comum e o individual ou entre a soberania e a internacionalização. Pode afirmar-se, pois, que o justo equilíbrio tem sido entendido como inerente ao próprio sistema da Convenção, ainda que se levantem algumas vozes discordantes, afirmando que uma retórica desta natureza (possibilitada por equação de tipo mais matemático ínsita no princípio da proporcionalidade ${ }^{8}$ ) obscurecerá considerações morais em que sempre deverá radicar a essência de um direito humano, tornando-os mais neutrais.

Parta-se, então, da noção convencional "numa sociedade democrática", inscrita nos artigos $6 .^{\circ},{ }^{\circ} .^{\circ} 1 ; 8 .^{\circ}, n .^{\circ} 2 ; 9 .^{\circ}, n .^{\circ} 2 ; 10 .^{\circ}, n .^{\circ} 2$; 11. ${ }^{\circ}$, n. $^{\circ} 2$ da CEDH e no artigo 2..$^{\circ}$, n. ${ }^{\circ}$ s 3 e 4 do Protocolo n. ${ }^{\circ} 4$. É ela muitas vezes a responsável pela invocação do princípio da proporcionalidade pelo Tribunal, considerando-se, pois, a necessidade de uma restrição numa sociedade democrática uma das pedras de toque do Direito dos Direitos Humanos. Porque tal cláusula é uma condição eminentemente política, para a densificar, o TEDH tem-se socorrido amiúde da teoria da margem de apreciação, defendendo que a proporcionalidade deve ser avaliada "à luz de todas as circunstâncias",

8 Apontando a ligação entre o raciocínio matemático e o princípio da proporcionalidade, vide, inter alia, CARLOS BERNAL PULIDO, El principio de proporcionalidad $y$ los derechos fundamentales: el principio de proporcionalidad como criterio para determinar el contenido de los derechos fundamentales vinculante para el legislador, 4. ed., Universidad Externado de Colombia, Bogotá, 2014, p. 54. 
desde que: (i) o fim seja legítimo; (ii) se esteja perante valores em colisão que gozem do mesmo status convencional.

A teoria da margem de apreciação não tinha assento literal na CEDH e o seu uso pelo TEDH foi, e é, muitas vezes, criticado. A situação encontra-se hoje parcialmente resolvida, na medida em que, segundo o Protocolo n. ${ }^{\circ}$ 15, tal teoria passa a constar do Preâmbulo da $\mathrm{CEDH}^{9}{ }^{10}$. Diz-se parcialmente porque, apesar de ter sido ratificado pelo Estado português, tal Protocolo ainda não se encontra em vigor ${ }^{11}$. A primeira invocação da margem de apreciação pelo TEDH data de 1961 (caso Lawless vs. Irlanda), só tendo vindo a ser referida pela Corte Interamericana de Direitos Humanos muitos anos depois (concretamente, em 1984 ${ }^{12}$ ). Em traços muito gerais, as principais críticas que são apontadas à margem de apreciação são as de ela constituir um aceno ao princípio da soberania dos Estados, em detrimento da efectiva protecção dos direitos humanos, e a da acentuação do relativismo/especificidade que essa margem nacional comporta, em prejuízo da universalidade de que estes direitos gozam $^{13}$. Contudo, crê-se que não se podem olvidar as vantagens

9 É o seguinte o texto: "Afirmando que, em conformidade com o princípio da subsidiariedade, incumbe em primeiro lugar às Altas Partes Contratantes assegurar os direitos e liberdades definidos nesta Convenção e nos respetivos Protocolos, e que ao fazê-lo elas gozam de uma margem de apreciação, sob a supervisão do Tribunal Europeu dos Direitos Humanos criado por esta Convenção" (itálico aditado).

10 Uma das ideias fundamentais que parece resultar deste Protocolo é a da insistência no princípio da subsidiariedade, segundo o qual incumbe em primeira linha aos Estados assegurar os direitos e liberdades protegidos pela Convenção. Neste sentido, os Estados gozam de uma margem de apreciação, embora, sempre, sob a supervisão do TEDH.

11 O Protocolo n. ${ }^{\circ} 15$ foi aberto à assinatura em Estrasburgo a 24 de Junho de 2013. Foi aprovado para ratificação, por Portugal, pela Resolução da Assembleia da República n. ${ }^{\circ}$ 231/2016 e ratificado pelo Decreto do Presidente da República n. ${ }^{\circ}$ 101/2016, publicados no Diário da República, 1. ${ }^{a}$ série, n. ${ }^{\circ} 227$, de 25 de Novembro de 2016. O respectivo instrumento de ratificação foi depositado junto do Secretário-Geral do Conselho da Europa a 16 de Janeiro de 2017.

12 Opinião Consultiva 4/84, de 19 de Janeiro de 1984 (num processo sobre naturalização interposto pela Costa Rica).

13 Equacionando a margem de apreciação em interrogações, pode-se sempre perguntar: como assegurar o universalismo dos direitos humanos se, por meio da 
de a margem de apreciação permitir a protecção de direitos num espaço que é multicultural, sendo o multiculturalismo um dos valores protegidos por instrumentos de direitos humanos ${ }^{14}$, e de expressar a sensibilidade do TEDH face aos Estados no que toca a temas polémicos, o que evita tensões entre as ordens jurídicas internas e a internacional. Com efeito, na integração teleológica e dinâmica de categorias convencionais como necessidade numa sociedade democrática ou proporcionalidade da restrição relativamente à finalidade existe sempre álea na interpretação, o que comporta o risco de desarmonia entre o direito europeu e o direito interno. Ora, o resultado prático pode ser um resultado concreto divergente. Prefere-se, pois, entender, e tal posição é hoje autorizada pelo aditamento efectuado através do Protocolo n. ${ }^{\circ} 15$, que a margem de apreciação é um critério hermenêutico jurisprudencial, destinado a evitar tensões e a possibilitar o diálogo entre as jurisdições, embora a interpretação, em cada concreto, tenha sempre que se fazer ainda dentro da esfera de protecção dos direitos humanos.

Acresce que não se pode olvidar que a par de possibilitar especial sensibilidade em temas controversos, a noção de margem de apreciação não tem sido entendida, pelo TEDH, de forma estanque. Exemplo disso é a alteração da jurisprudência do TEDH nos domínios da transsexualidade e dos partidos políticos. Com efeito, se até 2002, o Tribunal sustentou que relativamente a direitos de cidadãos transsexuais não havia uma abordagem unívoca na Europa, no caso Goodwin e I vs. Reino Unido (2002), o TEDH decidiu, de forma unânime, a favor dos requerentes e alegou que existem "tendências internacionais de aceitação social dos transexuais", bem como do "reconhecimento legal de uma nova identidade sexual após a operação de mudança de sexo". O relativismo temporal inerente à margem de apreciação nota-se, outrossim, na matéria de dissolução de partidos políticos. Nesta sede, se até 2003, a margem de apreciação era extensa, no caso Partido Refah vs. Turquia (2003),

margem de apreciação, cada Estado insiste em manter sua especificidade? Será que esta teoria reforça a ideia da fraca obrigatoriedade das normas de direito internacional e, consequentemente, das normas de direitos humanos?

14 Neste sentido vide, nomeadamente, art. 27. ${ }^{\circ}$ do PIDCP. 
o Tribunal veio afirmar que os Estados detêm apenas uma margem de apreciação muito reduzida (vide $\ 100$ ), em virtude da função dos partidos no quadro da democracia e do que é necessário "numa sociedade democrática".

Atendendo ao modo como o TEDH tem recorrido à margem de apreciação, pode fazer-se a seguinte metódica de ordenação (tendencial) consoante a "natureza do direito" e o "tipo de caso": há direitos absolutos (direito à vida e proibição da tortura), há direitos fortes (direito a um julgamento justo e direitos de liberdade), há direitos qualificados (direito à privacidade e liberdades de religião, associação, expressão e não discriminação) e há direitos fracos (propriedade, educação e direito a eleições livres).

Como já se disse, segundo o TEDH, o princípio da proporcionalidade incorpora padrões fundamentais de racionalidade, constituindo um poderoso instrumento hermenêutico para se avaliar da possibilidade de uma restrição (nunca se pode olvidar que este princípio teve o seu berço em preocupações relacionadas com a contenção do poder punitivo sobre o sujeito), considerando que se deve ter também em conta a margem de apreciação de que o Estado dispõe e cuja extensão variará, sensivelmente, segundo as circunstâncias, a natureza do direito protegido e a da ingerência ${ }^{15}$. No essencial, a operação hermenêutica consistirá: $1 .^{\circ}$, na análise sobre a interferência no direito; 2. ${ }^{\circ}$, na ponderação sobre a legitimidade do fim; $3 .^{\circ}$, na análise da legalidade da restrição no âmbito do direito interno (o que revela, na prática, o princípio do primado do Direito no âmbito do sistema

15 A título exemplificativo, veja-se o caso Stoll vs. Suiç̧a, $\ 105$ (2007): “Tratando-se de liberdade de imprensa, as autoridades têm uma margem de apreciação limitada para decidir se existe um "pressing social need" " ou o caso Demir e Baykara vs. Turquia, \119 (2008): "Quanto à necessidade de tal interferência numa sociedade democrática, o Tribunal reitera que podem ser impostas restrições legais ao exercício de direitos sindicais por membros das forças armadas. No entanto, é necessário lembrar que as excepções previstas no artigo $11 .^{\circ}$ [liberdade de reunião e de associação] devem ser interpretadas restritivamente; somente razões convincentes podem justificar restrições [...]. Ao determinar se nesses casos existe uma «necessidade» - e, portanto, um «pressing social need» - na acepção do artigo $11 .^{\circ}, \$ 2$, os Estados têm apenas uma margem de apreciação limitada, que é acompanhada de uma rigorosa supervisão europeia $[\ldots]$ ”. 
da Convenção) e $4 .^{\circ}$, na análise da proporcionalidade da medida. É, justamente, nesta fase que o Tribunal poderá fazer uso da margem de apreciação, o que leva a questionar se não haverá uma intrínseca ligação conceitual entre os dois conceitos no âmbito do sistema da Convenção. Efectivamente, na operação hermenêutica parece resultar que os princípios da proporcionalidade e da subsidiariedade são imanentes à noção de margem (nacional) de apreciação, pois se houver excesso por parte de um Estado, poderá haver violação do princípio da proporcionalidade, abrindo-se espaço, por força do princípio da subsidiariedade, para a intervenção do órgão jurisdicional europeu. É essa a razão para se ter questionado logo no início se estes dois conceitos - proporcionalidade e margem de apreciação - não serão uma equação do direito público europeu. A resposta tende a ser afirmativa, não obstante o significado próprio de cada um deles. 